Article

\title{
Partial Upgrading of Athabasca Bitumen Using Thermal Cracking
}

\author{
Thomas Kaminski and Maen M. Husein * (D) \\ Department of Chemical \& Petroleum Engineering, University of Calgary, Calgary, AB T2N 1N4, Canada; \\ takamins@ucalgary.ca \\ * Correspondence: mhusein@ucalgary.ca
}

Received: 19 April 2019; Accepted: 6 May 2019; Published: 9 May 2019

\begin{abstract}
The current industry practice is to mix bitumen with a diluent in order to reduce its viscosity before it can be pumped to refineries and upgraders. The recovery of the diluent and its recycling to the producers, on the other hand, pose major environmental and economic concerns. Hence, onsite partial upgrading of the extracted bitumen to pipeline specifications presents an attractive alternative. In this work, thermal cracking of Athabasca bitumen was carried out in an autoclave at $400{ }^{\circ} \mathrm{C}, 420^{\circ} \mathrm{C}$ and $440{ }^{\circ} \mathrm{C}$ in presence and absence of drill cuttings catalyst. At $400{ }^{\circ} \mathrm{C}$, despite no coke formation, the reduction in viscosity was insufficient, whereas at $440{ }^{\circ} \mathrm{C}$, the coke yield was significant, $\sim 20 \mathrm{wt} . \%$. A balance between yield and viscosity was found at $420^{\circ} \mathrm{C}$, with $88 \pm 5 \mathrm{wt} . \%$ liquid, $\sim 5 \mathrm{wt} . \%$ coke and a liquid viscosity and ${ }^{\circ} \mathrm{API}$ gravity of $60 \pm 20 \mathrm{cSt}$ and $23 \pm 3$, respectively. Additionally, the sulfur content and the Conradson carbon residue were reduced by $25 \%$ and $10 \%$, respectively. The catalytic thermal cracking at $420^{\circ} \mathrm{C}$ further improved the quality of the liquid product to $40 \pm 6 \mathrm{cSt}$ and $25 \pm 2$ ${ }^{\circ}$ API gravity, however at slightly lower liquid yield of $86 \pm 6 \mathrm{wt} . \%$. Both catalytic and non-catalytic cracking provide a stable liquid product, which by far exceeds pipeline standards. Although small relative to the energy required for upgrading in general, the pumping energy requirement for the partially upgraded bitumen was 3 times lower than that for diluted bitumen. Lastly, a 5-lump, 6-reaction, kinetic model developed earlier by our group successfully predicted the conversion of the bitumen to the different cuts.
\end{abstract}

Keywords: thermal cracking; bitumen; asphaltene; diluent; drill cuttings; partial upgrading

\section{Introduction}

Bitumen type petroleum makes up $15 \%$ of the current proven oil reserves [1,2]. The high content of asphaltenes and other heavy molecules in bitumen leads to major logistical problems during their production, transportation and handling [3]. Despite its large abundance, the cost of bitumen production, transportation and upgrading must be kept to a minimum for the resource to be profitable [4]. Several upgrading processes exist, falling under either carbon rejection or hydrogen addition processes. Carbon rejection processes, such as thermal cracking, are typically much more economical at the cost of product quality [5]. The addition of hydrogen, typically in the form of hydrocracking, while applicable to a wider range of feedstock and simultaneously achieves a more desirable octane number product, requires a high-pressure hydrogen atmosphere $[5,6]$. Thus, an upgrading process can be selected depending on the need and the balance between capital cost and product quality. Regardless of the upgrading route, the general guideline is to maximize the liquid yield, by minimizing coke and gas yields, while attaining high quality, stable liquid product $[6,7]$. In both types of processes, coke formation during upgrading poses significant operational problems such as catalyst deactivation [8,9]. In addition, the carbon dense coke product is of little value, despite the recent efforts to find markets for petroleum coke [10-13]. Gaseous type products, on the other 
hand, while compromising the liquid yield, could still hold some value as they could potentially be used for process heating.

Bitumen transportation is another aspect of bitumen handling that should be addressed. Due to the chemical nature of bitumen, its immediate transport following recovery is not feasible $[14,15]$. The current, most common, industry practice is to sufficiently reduce the viscosity of bitumen by mixing it with diluents $[7,14,16]$. Diluents are small chain hydrocarbons, e.g., natural gas condensates largely made up of naphtha [17], that are mixed with bitumen in order to reduce its viscosity and boost its ${ }^{\circ} \mathrm{API}$ gravity to pipeline standards. Pipeline requirements, while slightly varying, are typically a minimum acceptable viscosity of $350 \mathrm{cSt}$ and a maximum acceptable density of $940 \mathrm{~kg} \mathrm{~m}^{-3}\left({ }^{\circ} \mathrm{API}\right.$ gravity $=19)$ at $15.6{ }^{\circ} \mathrm{C}$ [18]. Therefore, the bitumen, a near solid substance at ambient conditions (viscosity $>200,000 \mathrm{cSt}$ ), must be mixed with sufficient amounts of diluent, typically $30 \mathrm{vol} \%$, in order to meet pipeline specifications $[6,7,19]$. This practice imposes a large economic strain on the cost of bitumen recovery, and increases the total cost of a barrel of bitumen by $20 \%[20,21]$. The recovery of diluents is usually carried out through distillation, or otherwise fed together with the bitumen into the upgrader resulting in a constant demand for resupply $[17,20]$. Subsequently, an inexpensive, simple to operate, onsite upgrading unit to achieve sufficient viscosity and density reduction offers a very attractive alternative.

Partial upgrading, specifically for heavier petroleum sources such as bitumen, has gained much prominence in recent years. A methane upgrading unit at relatively mild conditions of $400{ }^{\circ} \mathrm{C}$ and $3 \mathrm{MPa}$ for successful partial upgrading of bitumen in an autoclave was proposed [22-24]. Moreover, a low temperature viscosity reduction scheme to achieve upgrading in situ during production has been attempted to some success [25]. A hydro-conversion process was applied to achieve high sulfur and residue conversion in a fixed-bed reactor configuration [26]. Ideally, a smaller, simpler carbon rejection upgrading unit could be the most desirable option for achieving pipeline requirement on-site, as the potential high complexity and logistical problems of high-pressure hydrocrackers could be avoided [4,27]. Moreover, the product needs only to be stable during the duration of the pumping process. Therefore, a thermal cracking process, or if potentially better liquid quality is desired, a catalytic thermal cracking process would be an ideal choice. To ensure a low process cost and minimal complexity, drill cuttings, a waste by-product from drilling industry, could be used for catalytic upgrading [28]. Drill cuttings from a sandstone or shale formation are typically composed of alumina/silica, which serve as the most common base for a catalytic cracking catalyst. We have shown in our previous work that drill cuttings are effective thermal cracking catalyst $[29,30]$. They could also be used as effective hydrocracking catalysts, when promoted with hydrogenation elements [31]. As the drill cuttings are a waste product, their re-usability is not a must. They could simply be discarded upon settling after their use in the cracker [32].

In this study, thermal non-catalytic and catalytic cracking in the presence of drill cuttings of Athabasca bitumen was carried out in an autoclave. The objective of the study was to explore a simple, inexpensive upgrading process that could feasibly be used on-site to reduce the viscosity and density of bitumen to acceptable pipeline standards. Effort was made to ensure a one or two-step treatment process, i.e., a reactor unit and a settling unit, that would completely eliminate the need for a diluent. The accompanied reduction in the overall cost could prove very significant and lead to higher profit margin for bitumen in the current competitive oil market. The liquid product quality and yield were the main deciding factors on the efficacy of the proposed upgrading unit. Nevertheless, other factors such as liquid product stability were also considered.

\section{Results and Discussion}

\subsection{Catalyst Characterization}

Figure 1 presents FT-IR, $\mathrm{N}_{2}$ adsorption-desorption, SEM/EDX and particle size characterization of the drill cuttings. The FT-IR spectra in Figure 1a confirm the presence of LAS and BAS on the 
drill cuttings surface, per the visible peaks in the presence of pyridine at $1455 \mathrm{~cm}^{-1}$ and $1545 \mathrm{~cm}^{-1}$, respectively [33,34]. A slightly higher peak for LAS is found, suggesting that the ionic chain mechanism largely propagates through initial carbenium ion formation, potentially resulting in additional olefin formation, compared to catalytic cracking over BAS sites [35-38]. Bands at $1000 \mathrm{~cm}^{-1}$ and $600 \mathrm{~cm}^{-1}$ are associated with the natural silica framework and alumina bond stretching, respectively $[39,40]$. The $\mathrm{N}_{2}$ adsorption-desorption curve in Figure $1 \mathrm{~b}$ is of $\mathrm{H} 3$ type hysteresis, which suggests that the drill cuttings have little to no pore volume [41]. Additionally, the surface area estimated by BET is very small, especially compared to traditional zeolite catalysts which surface area typically falls in the $200-600 \mathrm{~m}^{2} \mathrm{~g}^{-1}$ range $[35,42,43]$.

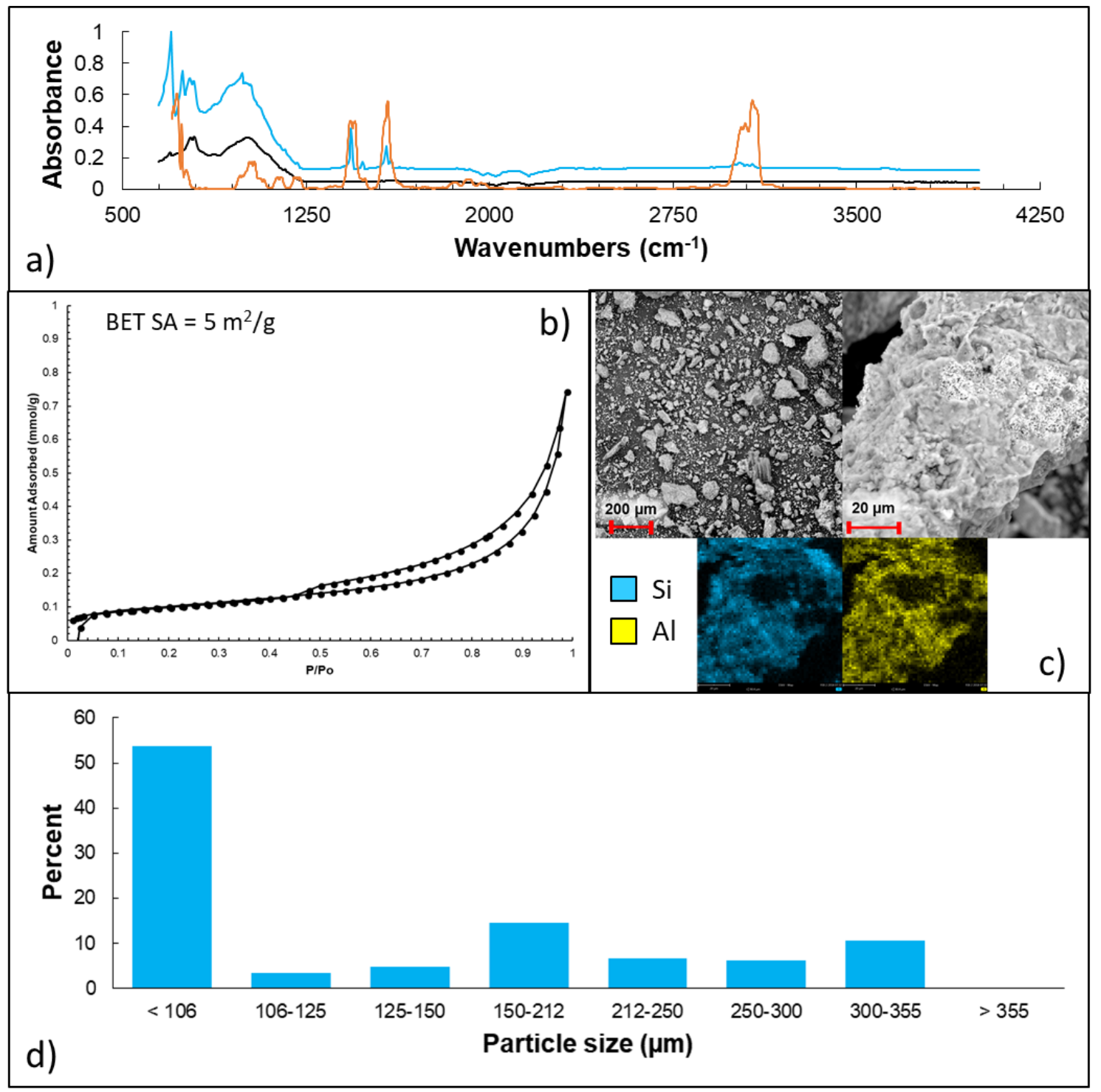

Figure 1. Characterization of drill cuttings. (a) FT-IR spectra of raw drill cuttings (black), raw drill cuttings + pyridine (blue) and pyridine (orange), (b) $\mathrm{N}_{2}$ adsorption-desorption curve with reported BET surface area, (c) SEM/EDX imaging of drill cuttings surface (blue = silicon, yellow = aluminum), (d) particle size distribution of raw drill cuttings used in upgrading runs.

However, despite lacking such traditional catalytic properties, the drill cuttings have been shown to possess not only surface catalytic activity, but an additional dispersing effect which is effective at reducing coke formation by exposing the precursor radicals to potential hydrogen donors in the reacting media [29,44-46]. To make up for the lack of catalytic activity, a large concentration, $10 \mathrm{wt} . \%$, 
of drill cuttings was confirmed effective in our previous work [30]. Even in a continuous reactor configuration partial upgrading, regeneration or recycling of the cuttings may not be necessary or even desired, as they are a waste product with no value to begin with. SEM/EDX imaging in Figure 1c further confirms the catalytic nature of the cuttings, as silicon and aluminum are present and well distributed on the surface of the cuttings, forming the $\mathrm{SiO}_{2} / \mathrm{Al}_{2} \mathrm{O}_{3}$ cracking base. Lastly, the particle size distribution in Figure 1d confirms that no cuttings with size $>355 \mu \mathrm{m}$ are present, and that the majority of the cuttings are $<106 \mu \mathrm{m}$. A smaller size catalyst is typically beneficial for a slurry cracking catalyst as it improves the mass and heat transfer effects in the reacting medium $[6,7,47]$.

\subsection{Temperature, Pressure and Energy Measurements}

Temperature and energy profiles formed during the upgrading runs can be found in Figure 2. Clearly, more severe runs required additional energy input throughout the duration of the upgrading. This suggests that the rate of endothermic reactions increased, and therefore additional heat input was required. It should be noted that we previously showed that the heat loss from the reactor arrangement may be important, but can never overshadow the heat of reactions [48]. Hence, the accelerated rates of cracking, which is known to increase with severity, increased the energy requirement by the reactor [49-51]. Catalytic runs required 10\% more energy on average, perhaps in part due to differences in the reaction paths in the presence of the drill cuttings. It has been previously confirmed that through a dispersing effect the drill cuttings promote the formation of volatile components at the expense of decreased maltene yield [29,30].

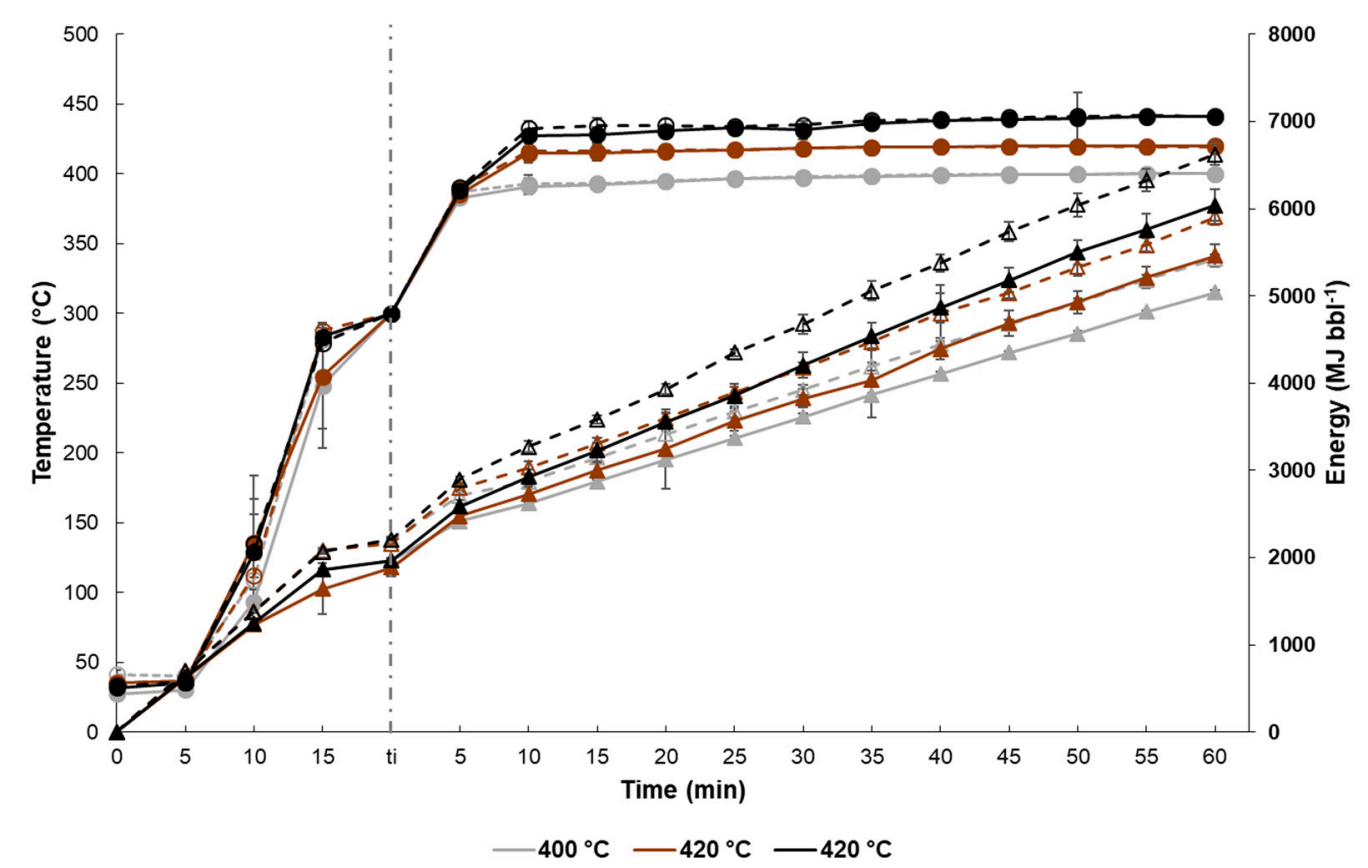

Figure 2. Temperature (circle) and energy (triangle) profiles for upgrading of Athabasca bitumen (solid $=$ control; empty $=$ catalytic). $\mathrm{t}_{\mathrm{i}}$ is the time that the temperature inside the autoclave reached $300{ }^{\circ} \mathrm{C}$.

This result is further reflected in Figure 3, which presents the pressure variation during upgrading runs. In general, and especially so for the $440{ }^{\circ} \mathrm{C}$ runs, the drill cuttings increased pressure evolution during upgrading, mostly in the form of condensable gases and volatiles which condensed to the liquid upon cooling to ambient conditions. The energetic requirement for the catalytic and non-catalytic thermal cracking fell in the range 5000-6500 MJ per barrel of feed. Pressure evolution was significant at higher temperatures, with pressures reaching upwards of 1000-1200 psi as a result of cracking. The difference between low and high temperature runs again stems from the fact that cracking reactions are much more favored at more severe temperatures [49-51]. 


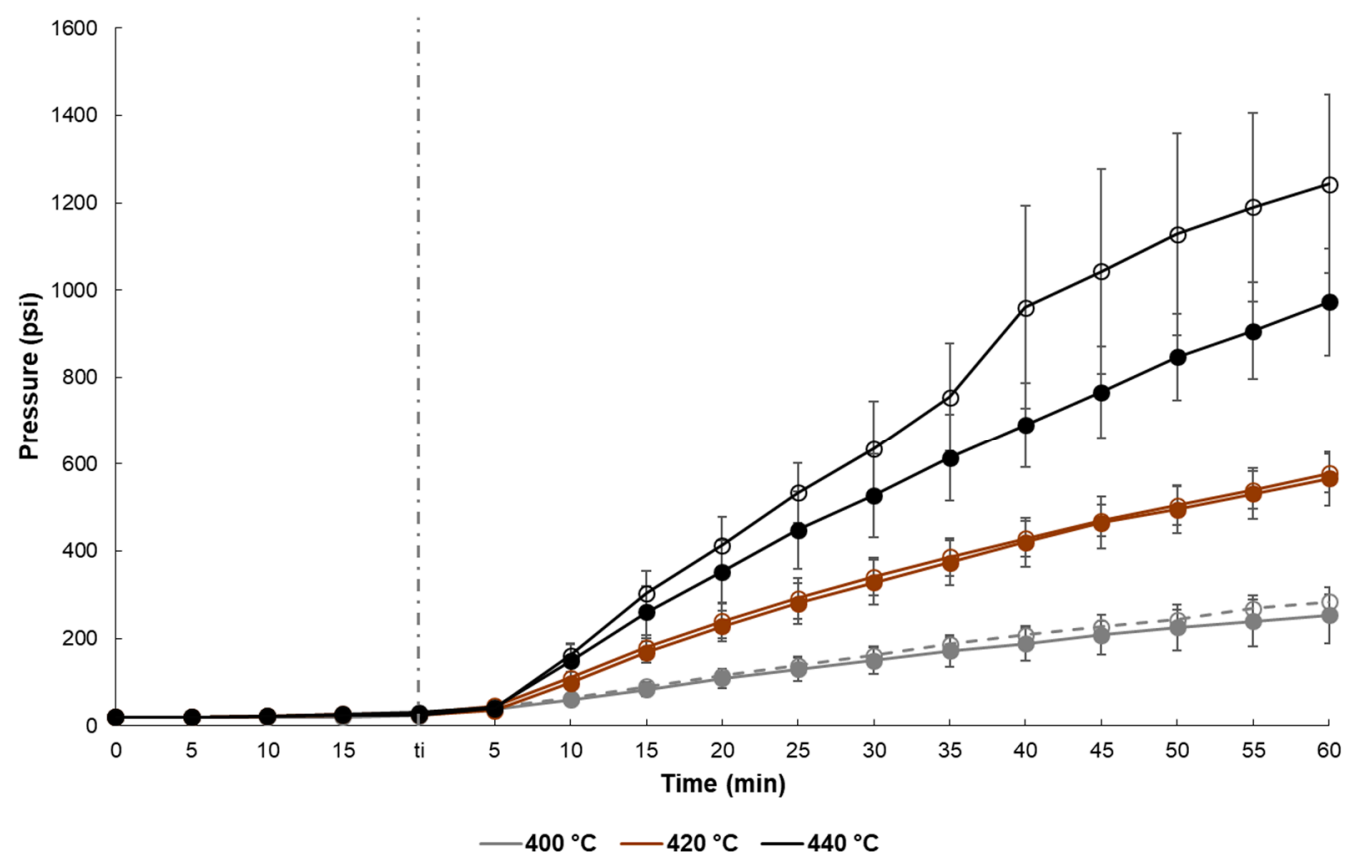

Figure 3. Pressure profiles for upgrading of Athabasca bitumen ( is the time that the temperature inside the autoclave reached $300{ }^{\circ} \mathrm{C}$.

\subsection{Product Yield and Quality}

Figure 4 presents the yield of the different products obtained from the catalytic and non-catalytic cracking of Athabasca bitumen, and Figure 5 presents quality measurements of the centrifuged liquid product at $400{ }^{\circ} \mathrm{C}, 420{ }^{\circ} \mathrm{C}$ and $440{ }^{\circ} \mathrm{C}$. At $400{ }^{\circ} \mathrm{C}$, almost no coke is formed for either control or catalytic runs resulting in $95.0 \pm 4.7 \mathrm{wt} . \%$ and $93.5 \pm 5.5 \mathrm{wt} . \%$ liquid product, respectively. However, while the viscosity is significantly reduced from the feed for both runs, $1100 \pm 230 \mathrm{cSt}$ and $720 \pm$ $100 \mathrm{cSt}$, respectively, it is well over the $350 \mathrm{cSt}$ requirement for pipelines. Additionally, ${ }^{\circ} \mathrm{API}$ gravity improvement is only 1-2 points from the feed for both control and catalytic runs. Thus, while the yields are encouraging, either the residence time or the severity of the reaction must be increased to further reduce the viscosity. A higher residence time could be employed, however, for the sake of partial upgrading, where the main objective is to obtain transportable crude, residence times should ideally be kept short in order to minimize reactor volumes.

At $420{ }^{\circ} \mathrm{C}$ the toluene insoluble (TI) yield becomes relatively significant with $4.2 \pm 0.8 \mathrm{wt} . \%$ and 5.3 $\pm 0.7 \mathrm{wt}$. \% coke being formed as a result of non-catalytic and catalytic thermal cracking, respectively. Likewise, the gas yield slightly increased in comparison to the runs at $400^{\circ} \mathrm{C}$. This is also reflected in Figure 3, where the pressure evolution was much more significant at $420^{\circ} \mathrm{C}$ compared with $400{ }^{\circ} \mathrm{C}$. Therefore, lower liquid yield, $87.9 \pm 4.6 \mathrm{wt} . \%$ and $85.7 \pm 5.9 \mathrm{wt} . \%$, was attained for both the control and the catalytic runs, respectively. It is worth noting that the volatile yield became significant at this temperature. On the other hand, the quality of liquid product improved by a large margin. The viscosity and ${ }^{\circ} \mathrm{API}$ gravity was $64 \pm 22 \mathrm{cSt}$ and $22.8 \pm 3.1$ for the control runs, and $42.3 \pm 5.7 \mathrm{cSt}$ and $24.9 \pm 1.6$ for the catalytic runs. This product quality is well under the $350 \mathrm{cSt}$ and $940 \mathrm{~kg} \mathrm{~m}^{-3}$ viscosity and density requirement for pipeline transport. Thus, only $\sim 5 \mathrm{wt} . \%$ of the liquid product was sacrificed in the form of coke to further push the quality of the liquid product to an acceptable standard. 


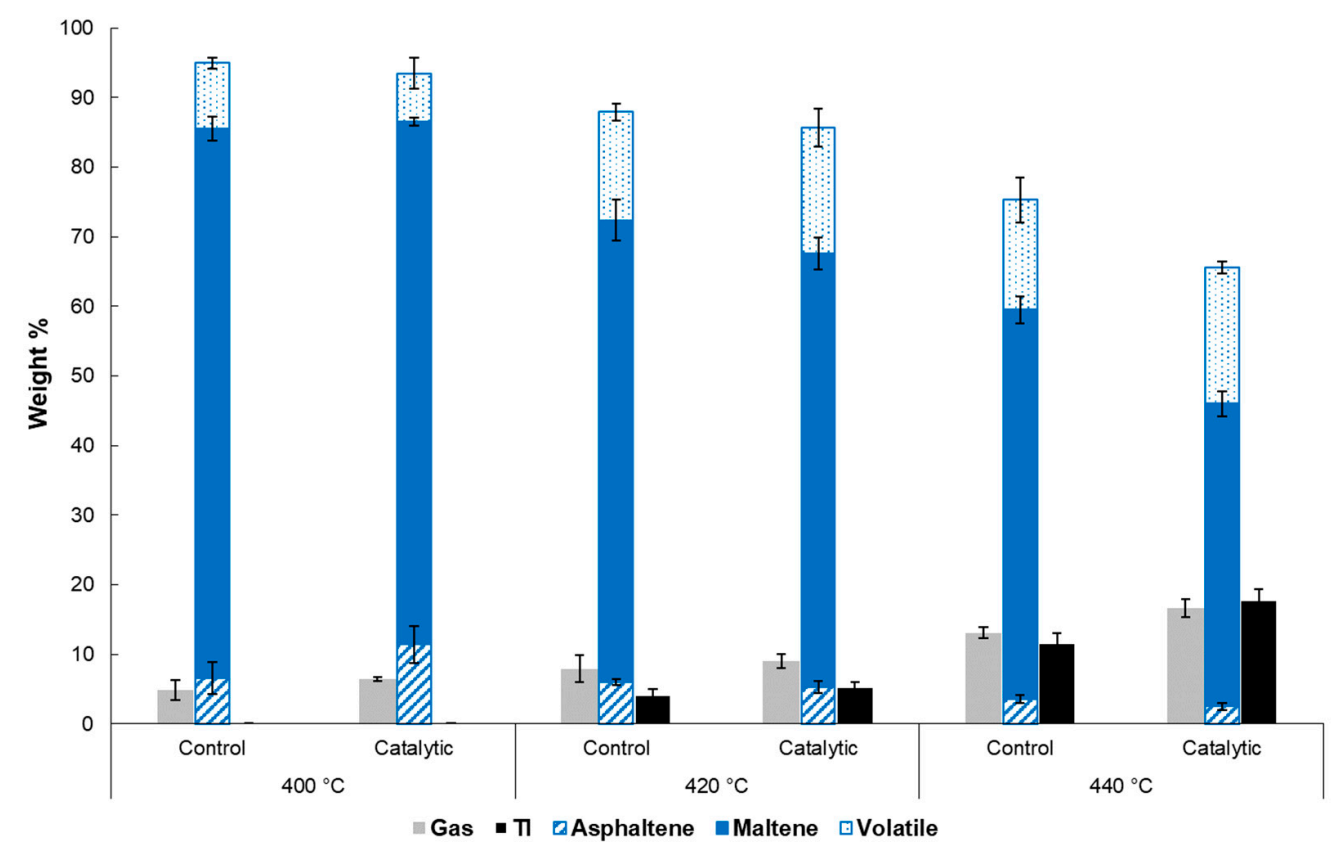

Figure 4. Product yields for upgrading of Athabasca bitumen at $400{ }^{\circ} \mathrm{C}, 420{ }^{\circ} \mathrm{C}$ and $440{ }^{\circ} \mathrm{C}$.

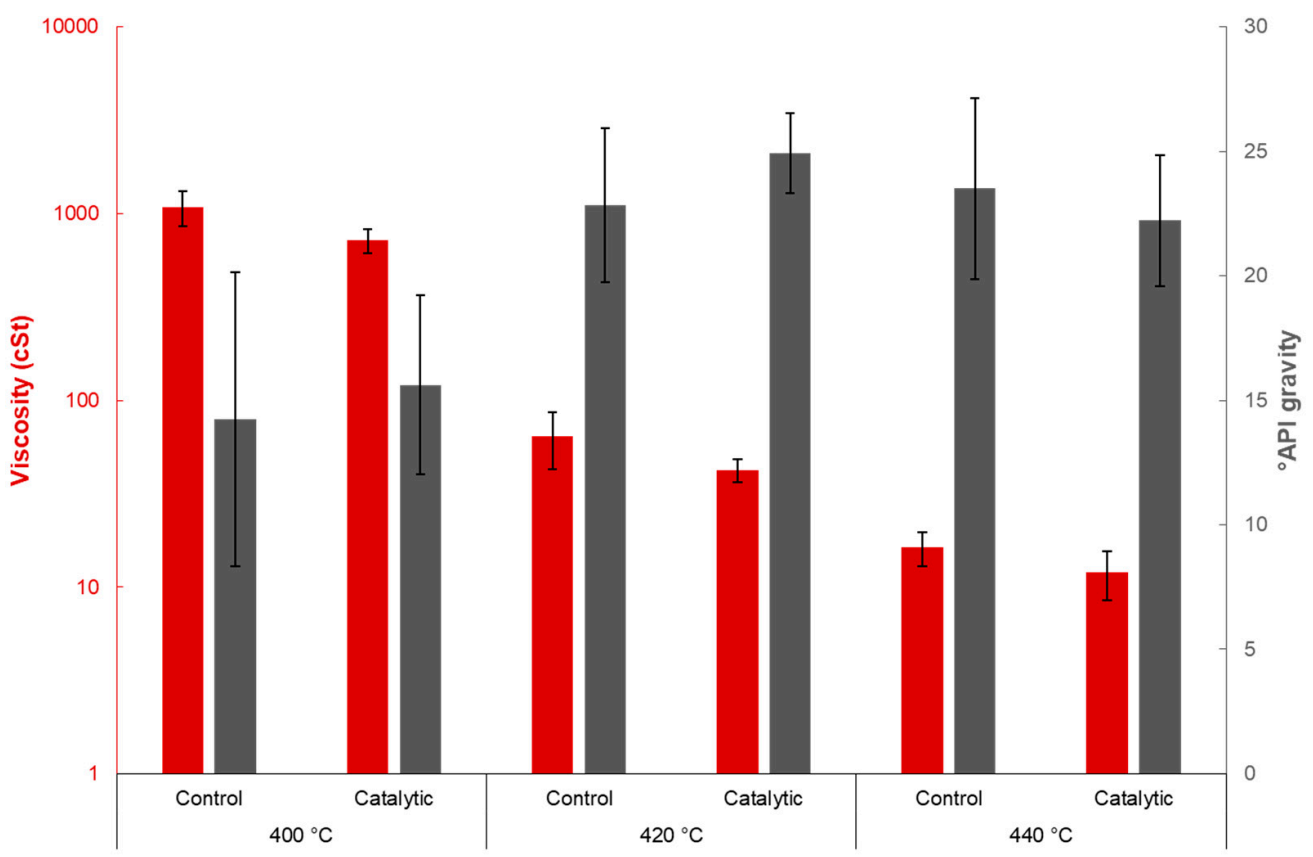

Figure 5. Kinematic viscosity and ${ }^{\circ} \mathrm{API}$ gravity measurements at $16^{\circ} \mathrm{C}$ of supernatant liquid product.

The liquid yield further degraded to $75.3 \pm 5.7 \mathrm{wt} . \%$ for the control runs and $65.5 \pm 3.2 \mathrm{wt} . \%$ for the catalytic runs when the severity of the reaction was pushed to $440{ }^{\circ} \mathrm{C}$. The TI and gas yields increased to $13.1 \pm 0.8 \mathrm{wt} . \%$ and $11.6 \pm 1.4 \mathrm{wt} . \%$ for the control runs, and $16.6 \pm 1.3 \mathrm{wt} . \%$ and $17.8 \pm 1.5$ wt. $\%$ for the catalytic runs. On the other hand, the viscosity and ${ }^{\circ} \mathrm{API}$ gravity of the liquid further changed to $16.3 \pm 3.4 \mathrm{cSt}$ and $23.5 \pm 3.6$ for the control runs, and $12 \pm 3.6 \mathrm{cSt}$ and $22.2 \pm 2.6$ for the catalytic runs. It is concluded that this further reduction in viscosity is not worth the substantially increased TI and reduced liquid yield, as the viscosity and density pipeline requirements were already met through upgrading at $420^{\circ} \mathrm{C}$. It should be noted that the depreciation of the ${ }^{\circ} \mathrm{API}$ gravity of the liquid product relative to the $420^{\circ} \mathrm{C}$ runs could result from entrained coke into the liquid product at the high coke yield encountered in these runs. 
Based on the conditions investigated, it would be recommended to run the process at $420{ }^{\circ} \mathrm{C}$ as it resulted in the best balance of yields and liquid quality. The upgrading could potentially be run with a shorter residence time, while still achieving acceptable viscosity and density. It is well-known that coke forms following an induction time [52,53]. Therefore, significant coke formation could be avoided if the residence time was limited, however the liquid quality must be monitored carefully. It is interesting to note that throughout the conditions, catalytic upgrading resulted in lower liquid yield than the control runs in exchange for slightly higher liquid quality. At $440{ }^{\circ} \mathrm{C}$ the difference in liquid yields between the control and the catalytic runs was upwards of $10 \mathrm{wt} . \%$ in return for not very significant quality improvement. This is most likely due to the increased yield of gaseous and volatile products, which reduced the liquid yield slightly, but in terms of the volatiles, contributed to increased liquid quality. On the other hand, at $400{ }^{\circ} \mathrm{C}$ the liquid yield difference was only $1 \mathrm{wt} . \%$, yet the viscosity difference was $\sim 400$ cSt. Clearly, a balance must be struck at the chosen operating conditions. Even though the drill cuttings are a waste material, it is entirely possible that the proposed process could be sufficiently run under thermal cracking, control conditions, if proved significantly advantageous.

Table 1 presents the Conradson carbon residue (CCR) and the sulfur content of the product oil of the non-catalytic and catalytic thermal cracking of Athabasca bitumen. At $400{ }^{\circ} \mathrm{C}, \mathrm{CCR}$ increased from the feed for both the control and the catalytic runs, however much less so for the catalytic runs. The increase in CCR most likely results from condensation and dehydrogenation reactions, and therefore formation of aromatic species, especially since no coke formed at $400{ }^{\circ} \mathrm{C}$, as a result of thermal cracking. In comparison, for the catalytic runs, lower CCR yield suggests that the drill cuttings promoted formation of reactions that led to paraffins and olefins, rather than aromatics, perhaps through the aforementioned dispersion effect and the abundance of LAS. At $420{ }^{\circ} \mathrm{C}$, the CCR yields were $11.6 \mathrm{wt} . \%$ and $10.4 \mathrm{wt} . \%$ for the control and catalytic runs, respectively, both showing a decrease from the feed. This is reflected by the apparent TI yield, as seen in Figure 4.

Table 1. Conradson carbon residue (CCR) and total sulfur content of upgraded bitumen samples.

\begin{tabular}{cccc}
\hline \multirow{2}{*}{ Feed } & & CCR (wt.\%) & Sulfur (wt.\%) \\
\cline { 3 - 4 } & & $\mathbf{1 2 . 9}$ & $\mathbf{5 . 4}$ \\
\hline \multirow{2}{*}{$400{ }^{\circ} \mathrm{C}$} & control & 20.9 & - \\
& catalytic & 14.2 & - \\
\hline \multirow{2}{*}{$420{ }^{\circ} \mathrm{C}$} & control & 11.6 & 4.1 \\
& catalytic & 10.4 & 4.2 \\
\hline \multirow{2}{*}{$440{ }^{\circ} \mathrm{C}$} & control & 14.8 & - \\
& catalytic & 8.4 & - \\
\hline
\end{tabular}

The majority of the aromatic species formed coalesced during upgrading and ended up in the coke fraction, resulting in a net decrease compared to the feed. Under carbon rejection conditions, $\sim 25 \%$ of the sulfur in the feed was removed from the liquid through either formation of gaseous species such as $\mathrm{H}_{2} \mathrm{~S}$ or ejection into the coke fraction. The drill cuttings did not improve sulfur reduction in comparison to the control runs, which suggests that the catalyst lacked affinity to the C-S bond. To further test the stability of the liquid product of the catalytic and the non-catalytic thermal cracking at $420^{\circ} \mathrm{C}$, viscosity and ${ }^{\circ} \mathrm{API}$ gravity was re-measured after a period of 3 weeks, as shown in Figure 6 . It is clear that the quality of the liquid has experienced some degradation possibly due to olefin instability and polymerization, but to no more than $10 \%$ deterioration in the viscosity and the ${ }^{\circ} \mathrm{API}$ gravity. The resulting liquid product is still in the acceptable range for pipeline transport (viscosity < $350 \mathrm{cSt},{ }^{\circ} \mathrm{API}$ gravity $>19$ ). It should be noted that a three-week timeframe is much more than expected to transport oil through pipelines [18]. 


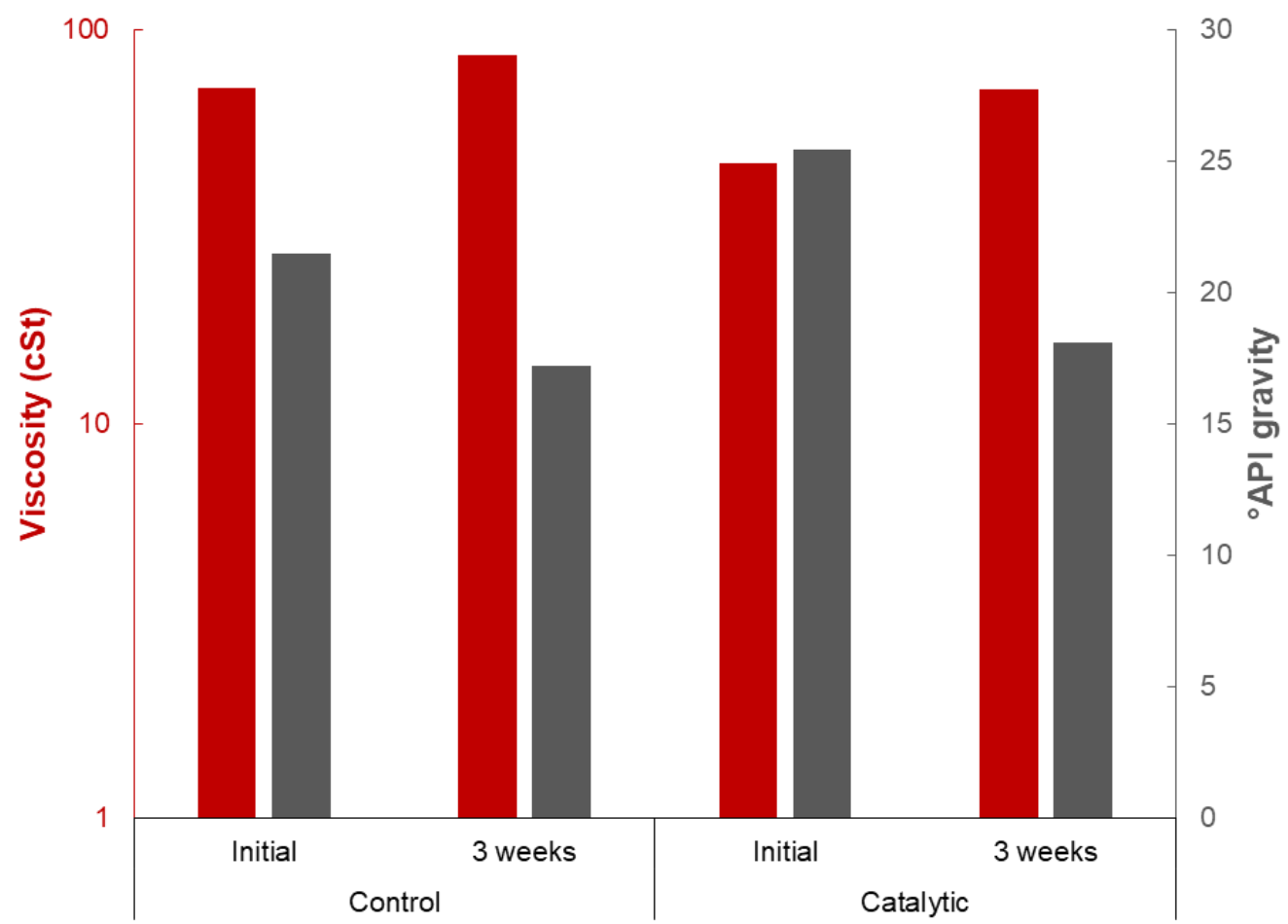

Figure 6. Product quality measurements after 3 week setting time for control and catalytic thermal cracking of Athabasca bitumen at $420^{\circ} \mathrm{C}$.

\subsection{Kinetic Modelling}

The results of the predictive capability for catalytic and non-catalytic thermal cracking of Athabasca bitumen at $400{ }^{\circ} \mathrm{C}$ and $420^{\circ} \mathrm{C}$ for $1 \mathrm{~h}$ are presented in Figure 7 . Fitted parameters are summarized in Table 2. The model predicted the overall liquid, coke and gas yields at both conditions to an excellent extent. For example, at $400{ }^{\circ} \mathrm{C}$, a $95.8 \mathrm{wt} . \%$ liquid yield was calculated through the model and $95.5 \pm$ $2.9 \mathrm{wt} . \%$ was experimentally obtained. Similarly, at $420^{\circ} \mathrm{C}$, a liquid yield of $87.6 \mathrm{wt} . \%$ was calculated through the model versus $85.7 \pm 5.9 \mathrm{wt} . \%$ experimentally measured. The discrepancy between the model prediction and the experiments is only limited to predicting the asphaltene and the volatile yields for the non-catalytic experiment. At $400{ }^{\circ} \mathrm{C}$ the model overpredicted an asphaltene yield of $14.1 \mathrm{wt} . \%$ compared with the experimental yield of $5.5 \pm 2.0 \mathrm{wt} . \%$, while underpredicted the distillate yield of $3.3 \mathrm{wt} . \%$ compared with the experimental yield of $9.9 \pm 0.6 \mathrm{wt} . \%$. This could be due to a difference in asphaltenes molecular structure between Athabasca bitumen and Arabian atmospheric residue, which in principle should contribute different products from their cracking [54-56]. Moreover, the model equations do not account for direct conversion of asphaltenes to volatiles, since this reaction was deemed relatively slow when fitting Arabian atmospheric residue data. On the other hand, the same observation was not reported for the catalytic cracking run, and except for predicting slightly less asphaltene conversion to gas and coke, the model captured the catalytic conversion of Athabasca bitumen to the different cuts much more accurately. The difference between the model prediction of the catalytic experimental results can still be attributed to the difference in the molecular structure of asphaltenes between the Arabian atmospheric residue and the Athabasca bitumen, whereas the enhanced predictability relative to the non-catalytic run are attribute the effective role of the catalyst at quenching the radicals and exposing the adsorbed asphaltenes to hydrogen donors from the solvent [57]. These reactions contribute to light and medium hydrocarbon distillate components, per our previous findings [57]. 


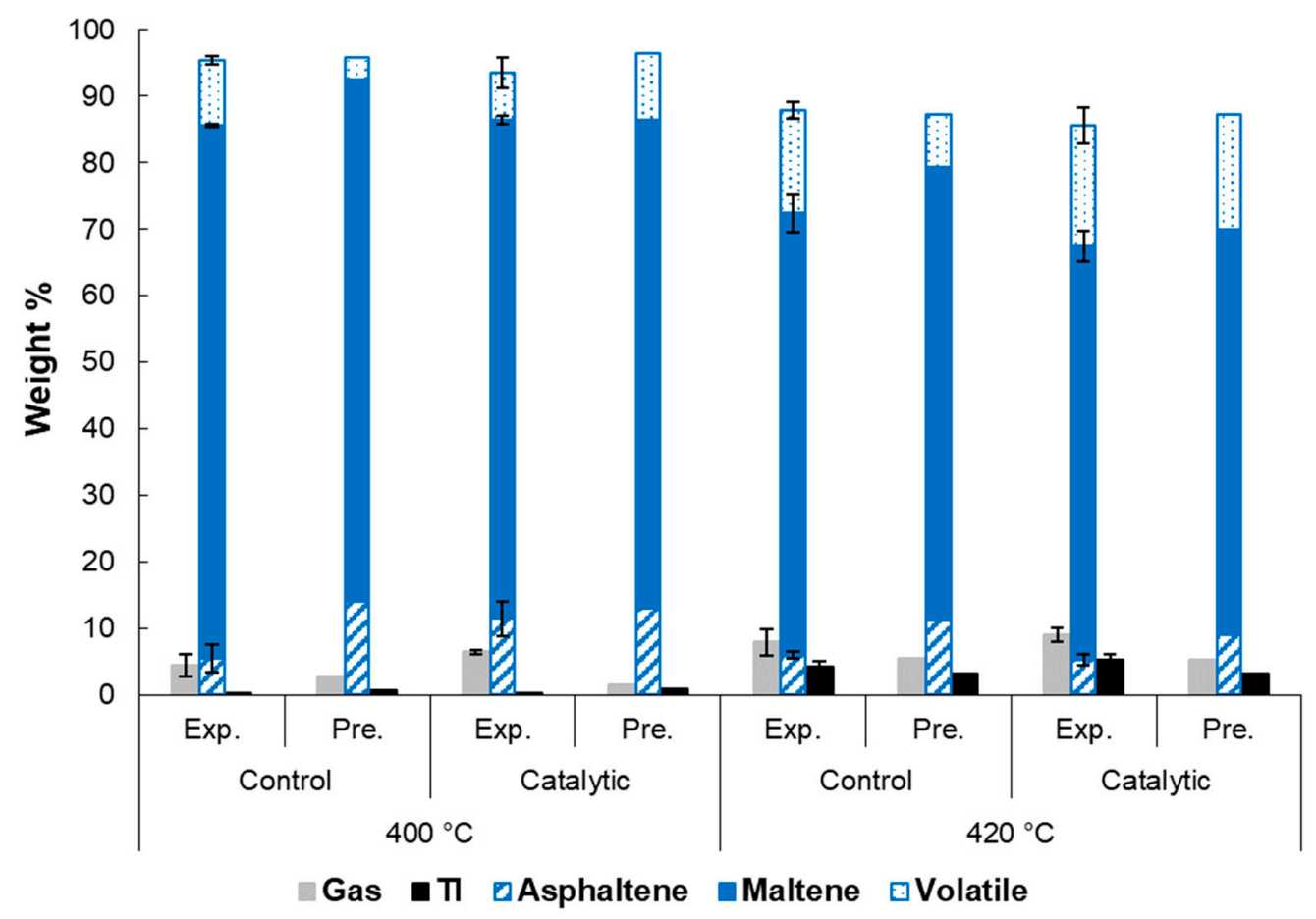

Figure 7. Comparison between experimental and predicted values for catalytic and non-catalytic thermal cracking at $400{ }^{\circ} \mathrm{C}$ and $420^{\circ} \mathrm{C}$ for $1 \mathrm{~h}$.

Table 2. Summary of optimized kinetic parameters [57].

\begin{tabular}{|c|c|c|c|c|c|c|}
\hline & \multicolumn{3}{|c|}{$k_{i}\left(h^{-1}\right)$} & \multirow{2}{*}{$E_{a}(\mathrm{~kJ} / \mathrm{mol})$} & \multirow{2}{*}{$\ln \left(k_{o}\right)$} & \multirow{2}{*}{$\mathbf{R}^{2}$} \\
\hline & $400^{\circ} \mathrm{C}$ & $410^{\circ} \mathrm{C}$ & $420^{\circ} \mathrm{C}$ & & & \\
\hline \multicolumn{7}{|c|}{ Non-Catalytic } \\
\hline 1 & 0.100 & 0.183 & 0.522 & 319.9 & 54.79 & 0.974 \\
\hline 2 & 0.175 & 0.209 & 0.368 & 143.3 & 23.80 & 0.910 \\
\hline 3 & 0.022 & 0.070 & 0.083 & 255.1 & 41.94 & 0.852 \\
\hline 4 & 0.038 & 0.054 & 0.116 & 213.4 & 34.81 & 0.951 \\
\hline 5 & 0.001 & 0.007 & 0.009 & 380.9 & 61.57 & 0.857 \\
\hline 6 & 0.015 & 0.033 & 0.077 & 315.2 & 52.13 & 0.999 \\
\hline \multicolumn{7}{|c|}{ Catalytic } \\
\hline 1 & 0.128 & 0.211 & 0.614 & 303.3 & 52.06 & 0.954 \\
\hline 2 & 0.035 & 0.143 & 0.323 & 433.6 & 74.22 & 0.979 \\
\hline 3 & 0.295 & 0.392 & 0.481 & 94.5 & 15.68 & 0.992 \\
\hline 4 & 0.051 & 0.091 & 0.147 & 204.0 & 33.51 & 0.998 \\
\hline 5 & 0.012 & 0.014 & 0.019 & 91.7 & 11.94 & 0.975 \\
\hline 6 & 0.101 & 0.159 & 0.213 & 144.8 & 23.62 & 0.986 \\
\hline
\end{tabular}

\subsection{Energy Analysis}

To fully comprehend the efficacy of the onsite upgrading process proposed here compared with diluent-based transport, energetic analysis was carried out. Sample calculations as well as a summary of the energy analysis can be found in the supporting material and Table S1. Our calculations show that the energy needed for pumping partially upgraded bitumen is approximately $30 \%$ of the energy needed to pump the diluted bitumen. It should be noted that pumping the diluent back to the producer only accounts for $\sim 3 \%$ of the total energy needed to pump the diluted bitumen, given its low viscosity and density. If one takes into account the energy needed to evaporate the diluent, however, the energy requirement for pumping partially upgraded bitumen falls down to only $0.02 \%$. However, our measurements and calculations showed that the energy needed for pumping $1 \mathrm{bbl}$ of bitumen, without heating, might be three orders of magnitude lower than the energy required for its upgrading. 
In this context, refinery upgrading might be more advantageous since it provides the option of only subjecting the vacuum residue stream to the upgrading process. Onsite upgrading, on the other hand, and in order to minimize the number of required units on-site, subjects the whole bitumen stream to thermal cracking. Assuming the same value of energy consumption between refinery and onsite upgrading, pumping diluted bitumen with refinery upgrading option consume $\sim 45 \%$ of the energy needed for the onsite upgrading of bitumen. It should be noted, however, that a high temperature and pressure hydrotreating process in a refinery may require much more energy than the simple thermal cracking process proposed in this work, especially when methane reforming step to supply the required hydrogen is taken into consideration. If, on the other hand, the diluted bitumen is pumped to an upgrader, where the whole bitumen stream is subjected to upgrading, then onsite upgrading would still make more energetic sense with energy savings of $\sim 30 \mathrm{MJ} / \mathrm{bbl}$.

It is worthwhile noting that the above analysis is made purely from an energetic standpoint. Economic consideration may prove that onsite upgrading of bitumen is probably much more profitable, especially given the specification/quality of the end product relative to the raw bitumen. Assuming same performance as the autoclave of this study, the volume of a continuous flow mixed tank reactor needed to upgrade $100 \mathrm{bbl}$ of bitumen product per day on-site would only be $1 \mathrm{~m}^{3}$. The energy needed for onsite upgrading may be supplied from the gas produced from the same well or a nearby gas well, as well as supplemented through the gas produced during upgrading.

\section{Materials and Methods}

\subsection{Materials}

Toluene (BDH 99.8\%, VWR, Canada) and n-heptane (BDH technical, VWR, Canada) were used for separating toluene insolubles (coke, catalyst, etc.) and asphaltenes from the product oil. Thermal and catalytic cracking runs were carried out under a $\mathrm{N}_{2}$ (99\% purity, Praxair Specialty Gas and Equipment, Calgary, AB, Canada) atmosphere. Athabasca bitumen (Cenovus, Calgary, AB, Canada) was used as the feedstock to the upgrading experiments. Properties of the feedstock are presented in Table 3.

Table 3. Properties of the Athabasca bitumen.

\begin{tabular}{cc}
\hline${ }^{\circ}$ API gravity & $13.1 \pm 2.2$ \\
Viscosity (cSt) & $>200,000$ \\
Asphaltenes (wt.\%) & $15.4 \pm 1.2$ \\
Maltenes (wt.\%) & $82.2 \pm 0.3$ \\
Sulfur (wt.\%) & 5.4 \\
CCR (wt.\%) & 12.9 \\
\hline
\end{tabular}

Dry sandstone drill cuttings were received from Executive Mat Service (EMS, Vancouver, BC, Canada). The as-received drill cuttings were purified by thoroughly washing with water followed by drying in an oven at $40^{\circ} \mathrm{C}$ for $12 \mathrm{~h}$. To reduce the drill cuttings to an acceptable size, they were first ground using a mortar and pestle and then sieved to filter out $>355 \mu \mathrm{m}$ cuttings. The particle size distribution of the resultant drill cuttings was determined using a tower of sieves with various mesh size. Scanning electron microscopy (SEM) (Quanta FEG 250, FEI Inc., Canada) and energy-dispersive X-ray spectroscopy (EDX) (Quantax 5030, Bruker, Montreal, QC, Canada) were performed to investigate the morphology and surface elemental analysis of the drill cuttings, respectively. $\mathrm{N}_{2}$ adsorption/desorption experiments were carried out at $-196{ }^{\circ} \mathrm{C}$ in order to evaluate the surface area of the drill cuttings. First, the drill cuttings were degassed at $150{ }^{\circ} \mathrm{C}$ under a $\mathrm{N}_{2}$ atmosphere for $24 \mathrm{~h}$, and then fed to a Micromeritics surface area analyzer (TriStar 2000, Micromeritics Instrument Corporation, Norcross, GA, USA). Surface area measurements were calculated using the Brunauer-Emmet-Teller (BET) method and total pore volume was estimated using the Barrett-Joyner-Halenda (BJH) method at a relative pressure (P/P0) of 0.99. Fourier-transform infrared spectroscopy (FT-IR) analysis was carried out on an Agilent Cary 630 (Agilent, Santa Clara, CA, USA) to determine Lewis and Brønsted acid site strength 
and concentration. As a control sample, the dry drill cuttings were introduced into the instrument and analyzed. Then, a drop of pyridine was introduced onto the drill cuttings and the sample was re-introduced into the instrument. Thus, both dry and pyridine drill cuttings spectra were collected and compared in order to determine the presence of Lewis and Brønsted acid sites.

\subsection{Upgrading}

The bitumen feed was first prepared by heating in a gravity convection oven (DX300, Yamato Scientific America Inc., Santa Clara, CA, USA) at $90{ }^{\circ} \mathrm{C}$ until it became pourable. The source sample was then mixed well with a metal rod to ensure homogeneity, and then a $50 \mathrm{~g}$ and $45 \mathrm{~g}$ samples were taken for the control and catalytic runs, respectively. A mass of $5 \mathrm{~g}$ drill cuttings was added to $45 \mathrm{~g}$ of oil for the catalytic runs to achieve a $10 \mathrm{wt} . \%(100,000 \mathrm{ppm})$ concentration. This concentration was previously found to be suitable for catalytic cracking of Athabasca vacuum residue [29,30]. Upgrading runs were performed in a $100 \mathrm{~mL}$ Parr autoclave (1.3 in. i.d. and 4.6 in. length, 4590 Micro Bench Top Reactor, Parr Instrument Company, Moline, IL, USA). When placed in the main apparatus, the reactor was surrounded by a heating jacket, which was electrically connected to a digital control unit which could monitor the temperature and pressure. A DI-50E meter (Electro-Meters Company Ltd., Pickering, $\mathrm{ON}$, Canada) was placed in series with the apparatus for monitoring heater usage. Once secured in the apparatus, the reactor was purged with $\mathrm{N}_{2}$ for $3 \mathrm{~min}$ to introduce a $\mathrm{N}_{2}$ atmosphere. Then, a pressure leak check was performed by holding the pressure within the autoclave at 100 psi for $5 \mathrm{~min}$, which upon completion, was released to achieve an initial atmospheric pressure in the reactor. The inlet and outlet were sealed tightly, and heating commenced at a rate of $25^{\circ} \mathrm{C} \mathrm{min}-1$. Upon reaching a temperature of $120^{\circ} \mathrm{C}$ inside the autoclave, mixing at a rate of $500 \mathrm{rpm}$ commenced. Our previous work showed that a lack of mixing resulted in additional formation of TI during upgrading, as well as improper mass and heat transfer caused by settled drill cuttings. The start point of the cracking reaction was considered from $300{ }^{\circ} \mathrm{C}$, as cracking is well known to commence in the range of $300-350{ }^{\circ} \mathrm{C}$ [58]. After reaching this point, the upgrading proceeded for $1 \mathrm{~h}$. Upon completion, the autoclave was quickly quenched several times using a cold-water bath, and then left to cool to ambient conditions $\left(20^{\circ} \mathrm{C}\right)$. The final pressure of the reactor was then recorded and any final, uncondensed, gases were slowly vented out of the system. The reactor was then removed from the main holding apparatus, liquid was scraped off the mixer shaft, and weighed. The overall gas yield of the reaction was taken to be the missing mass found by comparing the initial and final weights, as a result of the upgrading.

\subsection{Analysis}

After weighing, a liquid product sample was taken for characterization. A volume of $30 \mathrm{~mL}$ of the liquid product was poured into a centrifuge tube and centrifuged for $30 \mathrm{~min}$ at $5000 \mathrm{rpm}$. The supernatant was collected, and the bottoms of the tubes were weighed and added to the rest of the liquid still present in the reactor. Thus, two separate fractions, the supernatant and bottom fractions, were created out of the liquid product. The viscosity of the supernatant was measured using a cylindrical Brookfield viscometer (Model: LVDV-1 PRIME, Brookfield Engineering Laboratories Inc., Middleborough, MA, USA), and ${ }^{\circ}$ API gravity using a specific gravity bottle (Thomas Scientific, Swedesboro, NJ, USA) at $16^{\circ} \mathrm{C} .{ }^{\circ} \mathrm{API}$ gravity was calculated as follows:

$$
{ }^{\circ} \text { API gravity }=141.5 /\left(\left(\mathrm{m}_{\text {oil }}-\mathrm{m}_{\text {pycno }}\right) /\left(\left(\mathrm{m}_{\text {water }}-\mathrm{m}_{\text {pycno }}\right)-\left(\mathrm{m}_{\text {sol }}-\mathrm{m}_{\text {oil }}\right)\right)\right)-131.5
$$

The variables are measured as follows: $\mathrm{m}_{\mathrm{oil}}-$ pycnometer + few drops of oil, $\mathrm{m}_{\text {pycno }}-$ empty pycnometer, $\mathrm{m}_{\mathrm{water}}-$ pycnometer + water, $\mathrm{m}_{\mathrm{sol}}-$ pycnometer + few drops of oil + water. To ensure accuracy of results, the viscosity measurement was carried out at 5 different mixing speeds, and ${ }^{\circ} \mathrm{API}$ gravity was repeated 5 times. The supernatant was then washed with heptane at a 1:40 $v / v$ ratio and filtered using $25 \mu \mathrm{m}$ VWR filter paper. The filter paper was allowed to dry, and then placed into a double layer cellulose VWR thimble. The thimble was then introduced into a Soxhlet and washed with 
heptane for $24 \mathrm{~h}$. After washing, the thimble was dried and the mass of the extracted asphaltenes was determined by weighing the thimble and the filter paper. The heptane/maltene filtrate was introduced into a rotary evaporator (model: Hei-Vap value digital HL/G3, Heidolph Instruments GmbH \& Co., $\mathrm{KG}$, Schwabach, Germany) operating at a temperature of $93^{\circ} \mathrm{C}$ and pressure of $2 \mathrm{psi}$, where the heptane was evaporated out of the solution. After the final drop of condensate appeared, the evaporation was allowed to continue for $5 \mathrm{~min}$, in order to dry the leftover maltene fraction. The difference between the mass before and after was taken to be as the volatile yield of the supernatant fraction of the overall liquid product. The leftover maltene fraction was weighed and collected.

The bottoms fraction of the liquid product was thoroughly washed with toluene at a 1:40 v/v ratio and filtered using $25 \mu \mathrm{m}$ VWR filter paper, ejecting the TI out of the liquid. The filter papers were allowed to dry in ambient conditions for $24 \mathrm{~h}$, weighed, and then the dried TI solids collected. The toluene was then evaporated out of the system using a rotary evaporator operating at $93^{\circ} \mathrm{C}$ and 2 psi. Losses in the form of volatiles were considered by comparing weights of the feed to the rotary evaporator before and after evaporation. After toluene evaporation, similar to the supernatant, the asphaltenes were separated out using heptane at a 1:40 $v / v$ ratio, and $25 \mu \mathrm{m}$ VWR filter paper. As before, the dried filter paper was wrapped into a thimble and introduced into a Soxhlet and thoroughly washed with heptane for $24 \mathrm{~h}$. Finally, as with the supernatant, the heptane was evaporated, any remaining volatiles accounted for, and the remaining maltene fraction weighed and collected. To obtain $95 \%$ confidence intervals, three replicates were carried out for every upgrading run. The total sulfur concentration of the feedstock and the liquid product was measured using a Trace Sulfur Analyzer Model TS-100 (Mitsubishi Chemical Analytech Co., LTD, Shimotsuruma, Japan). Conradson carbon residue (CCR) content of similar oil samples was measured using thermogravimetric analysis (TGA), following a procedure outlined elsewhere [59].

\subsection{Kinetic Model}

A 5-lump, 6-reaction, kinetic model developed earlier by our group to describe the thermal catalytic and non-catalytic cracking of Arabian atmospheric residue was employed to predict the thermal cracking of bitumen [57]. Figure 8 shows the model reactions between the major lumps. The model parameters were optimized for thermal cracking of Arabian atmospheric residue and were directly employed here without data fitting $[29,57]$.

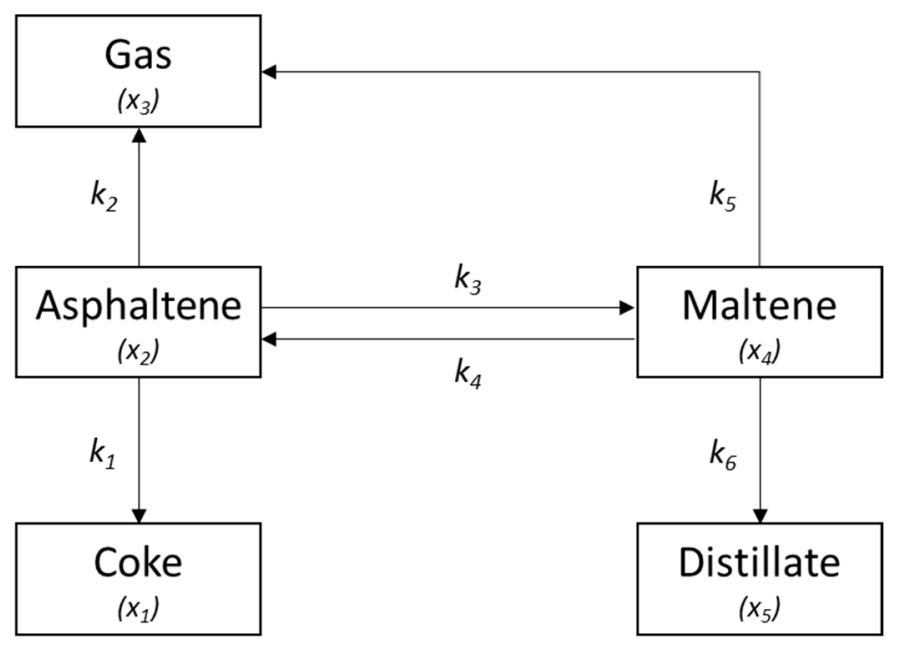

Figure 8. Five-lump, 6-reaction, thermal cracking kinetic model.

According to Figure 8, the reaction network is governed by the following equations:

$$
\text { coke } \rightarrow \mathrm{dx}_{1} / \mathrm{dt}=\mathrm{k}_{1} \mathrm{x}_{2} \mathrm{u}\left(\mathrm{t}-\mathrm{t}_{\text {induction }}\right)
$$




$$
\begin{array}{r}
\text { asphaltene } \rightarrow \mathrm{dx}_{2} / \mathrm{dt}=-\left(\mathrm{k}_{1}+\mathrm{k}_{2}+\mathrm{k}_{3}\right) \mathrm{x}_{2}+\mathrm{k}_{4} \mathrm{x}_{4} \\
\text { gas } \rightarrow \mathrm{dx}_{3} / \mathrm{dt}=-\mathrm{k}_{2} \mathrm{x}_{2}+\mathrm{k}_{5} \mathrm{x}_{3} \\
\text { maltene } \rightarrow \mathrm{dx} \mathrm{x}_{4} / \mathrm{dt}=-\left(\mathrm{k}_{4}+\mathrm{k}_{5}+\mathrm{k}_{6}\right) \mathrm{x}_{4}+\mathrm{k}_{3} \mathrm{x}_{2} \\
\text { distillate } \rightarrow \mathrm{dx} \mathrm{x}_{5} / \mathrm{dt}=\mathrm{k}_{6} \mathrm{x}_{4}
\end{array}
$$

A step function was introduced into (2) in order to account for the induction period of coke formation. A value of $30 \mathrm{~min}$ was used for the induction time in this work, based on previous observations, albeit various induction times are reported for different feeds in literature [60-62]. The fitted parameters were optimized by reducing root mean squared deviations (RMSE) between the model and the experimental Arabian atmospheric residue data using a Monte Carlo type procedure [57].

\title{
4. Conclusions
}

Thermal cracking of Athabasca bitumen was carried out in a batch reactor for a range of temperature between $400{ }^{\circ} \mathrm{C}$ and $440{ }^{\circ} \mathrm{C}$ and $1 \mathrm{~h}$ duration. At $400{ }^{\circ} \mathrm{C}$, for both catalytic and non-catalytic runs, minimal amounts of coke were produced, however the viscosity of the product oil was $>350 \mathrm{cSt}$, and therefore insufficient for pipeline standards. At $420{ }^{\circ} \mathrm{C}$ for both catalytic and non-catalytic runs, a good balance between coke yield and liquid yield and quality is found. Only $\sim 5 \mathrm{wt} . \%$ coke formed in return for a viscosity of $\sim 50 \mathrm{cSt}$ and ${ }^{\circ} \mathrm{API}$ gravity of $>25$. A sulfur and CCR reduction of $25 \%$ and $10 \%$, respectively, were achieved from the feed at $420{ }^{\circ} \mathrm{C}$. The liquid product was shown to be stable with only $10 \%$ depreciation in viscosity and ${ }^{\circ}$ API gravity over a period of 3 weeks, with the liquid still remaining well within acceptable pipeline standards. At $440{ }^{\circ} \mathrm{C}$, the non-catalytic run produced $\sim 75 \mathrm{wt} . \%$ liquid, and catalytic run produced $\sim 65 \mathrm{wt} . \%$ liquid with only slight improvement in quality in comparison with the runs at $420^{\circ} \mathrm{C}$. The required thermal energy input into the process was measured to fall between 5500 and 5900 MJ per barrel of feed, accounting for potential heat losses. Overall energetic analysis showed that the pumping requirement for the partially upgraded product was 3 times lower than that for diluted bitumen, without accounting for diluent recovery through evaporation.

Supplementary Materials: The following are available online at http://www.mdpi.com/2073-4344/9/5/431/s1, Table S1: Energetic comparison between diluted bitumen and partial upgrading pathways.

Author Contributions: Conceptualization, T.K. and M.M.H.; methodology, T.K. and M.M.H.; validation, T.K. formal analysis, T.K.; investigation, T.K.; resources, M.M.H.; writing-original draft preparation, T.K.; writing—review and editing, T.K., M.M.H.; supervision, M.M.H.; funding acquisition, M.M.H.

Funding: This project did not receive direct funding from any source.

Acknowledgments: The authors would like to thank Cenovus for providing Athabasca bitumen and Executive Service Mat for providing drill cuttings. T.K. acknowledges the Schulich School of Engineering for their financial support.

Conflicts of Interest: The authors declare no conflict of interest.

\author{
Abbreviations \\ The following abbreviations are used in the article: \\ BAS Brønsted acid sites \\ CCR Conradson carbon residue \\ LAS Lewis acid sites \\ TI Toluene insoluble
}

\section{References}

1. Rogner, H.H. An Assessment of World Hydrocarbon Resources. Ann. Rev. Energy Environ. 1997, 22, $217-262$. [CrossRef] 
2. EIA. Annual Energy Outlook 2016; U.S. Energy Information Administration: Washington, DC, USA, 2016; p. ES-5.

3. Gawel, I.; Bociarska, D.; Biskupski, P. Effect of asphaltenes on hydroprocessing of heavy oils and residua. Appl. Catal. A Gen. 2005, 295, 89-94. [CrossRef]

4. Demirbas, A.; Bafail, A.; Nizami, A.S. Heavy oil upgrading: Unlocking the future fuel supply. Pet. Sci. Technol. 2016, 34, 303-308. [CrossRef]

5. Castañeda, L.C.; Muñoz, J.A.D.; Ancheyta, J. Current situation of emerging technologies for upgrading of heavy oils. Catal. Today 2014, 220-222, 248-273. [CrossRef]

6. Speight, J.G. Heavy and Extra-Heavy Oil Upgrading Technologies; Gulf Professional Publishing: Woburn, MA, USA, 2013; ISBN 9780124045705.

7. Gray, M.R. Upgrading Oilsands Bitumen and Heavy Oil; University of Alberta: Edmonton, AB, Canada, 2015.

8. Prajapati, R.; Kohli, K.; Maity, S.K.; Garg, M.O. Coking propensity during hydroprocessing of vacuum residues, deasphalted oils, and asphaltenes. Fuel 2017, 203, 514-521. [CrossRef]

9. Carrillo, J.A.; Corredor, L.M. Upgrading of heavy crude oils: Castilla. Fuel Process. Technol. 2013, 109, $156-162$. [CrossRef]

10. Montes, V.; Hill, J.M. Activated carbon production: Recycling KOH to minimize waste. Mater. Lett. 2018, 220, 238-240. [CrossRef]

11. Tan, M.H.; Zheng, J.T.; Li, P.; Noritatsu, T.; Wu, M.B. Preparation and modification of high performance porous carbons from petroleum coke for use as supercapacitor electrodes. Xinxing Tan Cailiao/New Carbon Mater. 2016, 31, 343-351. [CrossRef]

12. Manasrah, A.D.; Nassar, N.N.; Ortega, L.C. Conversion of petroleum coke into valuable products using oxy-cracking technique. Fuel 2018, 215, 865-878. [CrossRef]

13. Edwards, L.; Vogt, F.; Robinette, M.; Love, R.; Ross, A.; Mcclung, M.; Roush, R.; Morgan, W. Use of Shot Coke as an Anode Raw Material. In Essential Readings in Light Metals: Electrode Technology for Aluminum Production; Springer International Publishing: Cham, Switzerland, 2013; ISBN 9781118636633.

14. Czarnecki, J.; Radoev, B.; Schramm, L.L.; Slavchev, R. On the nature of Athabasca Oil Sands. Adv. Colloid Interface Sci. 2005, 114-115, 53-60. [CrossRef]

15. Attanasi, E.D.; Meyer, R.F. Natural Bitumen and Extra-Heavy Oil. Surv. Energy Resour. 2007, $93-117$. [CrossRef]

16. Hart, A. A review of technologies for transporting heavy crude oil and bitumen via pipelines. J. Pet. Explor. Prod. Technol. 2014, 4, 327-336. [CrossRef]

17. Shah, A.; Fishwick, R.; Wood, J.; Leeke, G.; Rigby, S.; Greaves, M. A review of novel techniques for heavy oil and bitumen extraction and upgrading. Energy Environ. Sci. 2010, 3, 700. [CrossRef]

18. Martínez-Palou, R.; de Lourdes Mosqueira, M.; Zapata-Rendón, B.; Mar-Juárez, E.; Bernal-Huicochea, C.; de la Cruz Clavel-López, J.; Aburto, J. Transportation of heavy and extra-heavy crude oil by pipeline: A review. J. Pet. Sci. Eng. 2011, 75, 274-282. [CrossRef]

19. Ramos-Pallares, F.; Schoeggl, F.F.; Taylor, S.D.; Satyro, M.A.; Yarranton, H.W. Predicting the Viscosity of Hydrocarbon Mixtures and Diluted Heavy Oils Using the Expanded Fluid Model. Energy Fuels 2016, 30, 3575-3595. [CrossRef]

20. Verma, A.; Nimana, B.; Olateju, B.; Rahman, M.M.; Radpour, S.; Canter, C.; Subramanyam, V.; Paramashivan, D.; Vaezi, M.; Kumar, A. A techno-economic assessment of bitumen and synthetic crude oil transport (SCO) in the Canadian oil sands industry: Oil via rail or pipeline? Energy 2017, 124, 665-683. [CrossRef]

21. Miadonye, A.; Latour, N.; Puttagunta, V.R. Correlation for viscosity and solvent mass fraction of bitumen-diluent mixtures. Pet. Sci. Technol. 2000, 18,1-14. [CrossRef]

22. He, P.; Luan, Y.; Zhao, L.; Cheng, W.; Wu, C.; Chen, S.; Song, H. Catalytic bitumen partial upgrading over Ag-Ga/ZSM-5 under methane environment. Fuel Process. Technol. 2017, 156, 290-297. [CrossRef]

23. Zhao, L.; He, P.; Jarvis, J.; Song, H. Catalytic Bitumen Partial Upgrading under Methane Environment over Ag-Mo-Ce/ZSM-5 Catalyst and Mechanistic Study Using N-Butylbenzene as Model Compound. Energy Fuels 2016, 30. [CrossRef]

24. He, P.; Zhao, L.; Song, H. Bitumen partial upgrading over Mo/ZSM-5 under methane environment: Methane participation investigation. Appl. Catal. B Environ. 2017, 201, 438-450. [CrossRef]

25. Yañez Jaramillo, L.M.; De Klerk, A. Partial Upgrading of Bitumen by Thermal Conversion at $150-300{ }^{\circ} \mathrm{C}$. Energy Fuels 2018, 32, 3299-3311. [CrossRef] 
26. Xing, T.; Alvarez-Majmutov, A.; Chen, J. Bitumen partial upgrading by mild hydroprocessing in a fixed-bed reactor. Fuel 2019, 235, 696-702. [CrossRef]

27. Valavarasu, G.; Bhaskar, M.; Balaraman, K.S. Mild Hydrocracking-A Review of the Process, Catalysts, Reactions, Kinetics, and Advantages. Pet. Sci. Technol. 2003, 21, 1185-1205. [CrossRef]

28. Ball, A.S.; Stewart, R.J.; Schliephake, K. A review of the current options for the treatment and safe disposal of drill cuttings. Waste Manag. Res. 2012, 30, 457-473. [CrossRef]

29. Kaminski, T.; Husein, M.M. Thermal cracking of atmospheric residue versus vacuum residue. Fuel Process. Technol. 2018, 181, 331-339. [CrossRef]

30. Eshraghian, A.; Husein, M.M. Catalytic thermal cracking of Athabasca VR in a closed reactor system. Fuel 2018, 217, 409-419. [CrossRef]

31. Kaminski, T.; Sheng, Q.; Husein, M.; Kaminski, T.; Sheng, Q.; Husein, M.M. Hydrocracking of Athabasca Vacuum Residue Using Ni-Mo-Supported Drill Cuttings. Catalysts 2019, 9, 216. [CrossRef]

32. Gary, J.H.; Handwerk, G.E.; Kaiser, M.J. Petroleum Refining: Technology and Economics; CRC Press: Boca Raton, FL, USA, 2007.

33. Kondo, J.N.; Nishitani, R.; Yoda, E.; Yokoi, T.; Tatsumi, T.; Domen, K. A comparative IR characterization of acidic sites on HY zeolite by pyridine and CO probes with silica-alumina and $\gamma$-alumina references. Phys. Chem. Chem. Phys. 2010, 12, 11576. [CrossRef] [PubMed]

34. Parry, E.P. An infrared study of pyridine adsorbed on acidic solids. Characterization of surface acidity. J. Catal. 1963, 2, 371-379. [CrossRef]

35. Wielers, A.F.H.; Vaarkamp, M.; Post, M.F.M. Relation between properties and performance of zeolites in paraffin cracking. J. Catal. 1991, 127, 51-66. [CrossRef]

36. Jacob, S.M.; Gross, B.; Voltz, S.E.; Weekman, V.W. A lumping and reaction scheme for catalytic cracking. AIChE J. 1976, 22, 701-713. [CrossRef]

37. Decroocq, D. Catalytic Cracking of Heavy Petroleum Fractions; Editions Technip: Paris, France, 1984.

38. Regali, F.; Liotta, L.F.; Venezia, A.M.; Montes, V.; Boutonnet, M.; Järås, S. Effect of metal loading on activity, selectivity and deactivation behavior of $\mathrm{Pd} /$ silica-alumina catalysts in the hydroconversion of $\mathrm{n}$-hexadecane. Catal. Today 2014, 223, 87-96. [CrossRef]

39. Beganskiene, A.; Sirutkaitis, V.; Kurtinaitiene, M.; Juskenas, R.; Kareiva, A. FTIR, TEM and NMR linvestigations of Stöber Silica Nanoparticles. Mater. Sci. 2004, 10, 287-290.

40. Contreras, C.A.; Sugita, S.; Ramos, E. Preparation of Sodium Aluminate From Basic Aluminium Sulfate. AZo J. Mater. Online 2006, 1-13. [CrossRef]

41. Thommes, M. Physical adsorption characterization of nanoporous materials. Chemie-Ingenieur-Technik 2010, 82, 1059-1073. [CrossRef]

42. Ali, M.A.; Tatsumi, T.; Masuda, T. Development of heavy oil hydrocracking catalysts using amorphous silica-alumina and zeolites as catalyst supports. Appl. Catal. A Gen. 2002, 233, 77-90. [CrossRef]

43. Kaminski, T.; Anis, S.F.; Husein, M.M.; Hashaikeh, R. Hydrocracking of Athabasca VR Using NiO-WO3 Zeolite-Based Catalysts. Energy Fuels 2018, 32, 2224-2233. [CrossRef]

44. Sanaie, N.; Watkinson, A.P.; Bowen, B.D.; Smith, K.J. Effect of minerals on coke precursor formation. Fuel 2001, 80, 1111-1119. [CrossRef]

45. Nhieu, P.; Liu, Q.; Gray, M.R. Role of water and fine solids in onset of coke formation during bitumen cracking. Fuel 2016, 166, 152-156. [CrossRef]

46. Tanabe, K.; Gray, M.R. Role of fine solids in the coking of vacuum residues. Energy Fuels 1997, 11, 1040-1043. [CrossRef]

47. Maxwell, I.E. Zeolite catalysis in hydroprocessing technology. Catal. Today 1987, 1, 385-413. [CrossRef]

48. Eshraghian, A.; Husein, M.M. Thermal cracking of Athabasca VR and bitumen and their maltene fraction in a closed reactor system. Fuel 2017, 190, 396-408. [CrossRef]

49. Singh, J.; Kumar, M.M.; Saxena, A.K.; Kumar, S. Reaction pathways and product yields in mild thermal cracking of vacuum residues: A multi-lump kinetic model. Chem. Eng. J. 2005, 108, 239-248. [CrossRef]

50. Del Bianco, A.; Panariti, N.; Anelli, M.; Beltrame, P.L.; Carniti, P. Thermal cracking of petroleum residues. 1. Kinetic analysis of the reaction. Fuel 1993, 72, 75-80. [CrossRef]

51. Phillips, C.R.; Haidar, N.I.; Poon, Y.C. Kinetic models for the thermal cracking of Athabasca bitumen. Fuel 1985, 64, 678-691. [CrossRef] 
52. Gray, M.R.; McCaffrey, W.C.; Huq, I.; Le, T. Kinetics of cracking and devolatilization during coking of Athabasca residues. Ind. Eng. Chem. Res. 2004, 43, 5438-5445. [CrossRef]

53. Gentzis, T.; Rahimi, P.; Malhotra, R.; Hirschon, A.S. Effect of carbon additives on the mesophase induction period of Athabasca bitumen. Fuel Process. Technol. 2001, 69, 191-203. [CrossRef]

54. Lababidi, H.M.S.; Sabti, H.M.; Alhumaidan, F.S. Changes in asphaltenes during thermal cracking of residual oils. Fuel 2014, 117, 59-67. [CrossRef]

55. Ranjbar, M.; Pusch, G. Pyrolysis and combustion kinetics of crude oils, asphaltenes and resins in relation to thermal recovery processes. J. Anal. Appl. Pyrolysis 1991, 20, 185-196. [CrossRef]

56. Asgharzadeh Shishavan, R.; Ghashghaee, M.; Karimzadeh, R. Investigation of kinetics and cracked oil structural changes in thermal cracking of Iranian vacuum residues. Fuel Process. Technol. 2011, 92, 2226-2234. [CrossRef]

57. Kaminski, T.; Husein, M.M.M. Kinetic Modelling of Thermal Cracking of Arabian Atmospheric and Vacuum Residue. Fuel Process. Technol. 2019, 189, 89-97. [CrossRef]

58. Singh, J.; Kumar, M.M.; Saxena, A.K.; Kumar, S. Studies on thermal cracking behavior of residual feedstocks in a batch reactor. Chem. Eng. Sci. 2004, 59, 4505-4515. [CrossRef]

59. Cardillo, P.; Galtieri, A. Determination of the Carbon Residue of Fuel Oils by Means of Thermogravimetry. Riv. Combust. 1987, 41, 1-5.

60. Jia, N.; Moore, R.G.; Mehta, S.A.; Ursenbach, M.G. Kinetic modelling of thermal cracking and low temperature oxidation reactions. J. Can. Pet. Technol. 2006. [CrossRef]

61. Radmanesh, R.; Chan, E.; Gray, M.R. Modeling of mass transfer and thermal cracking during the coking of Athabasca residues. Chem. Eng. Sci. 2008, 63, 1683-1691. [CrossRef]

62. Martínez, M.T.; Benito, A.M.; Callejas, M.A. Thermal cracking of coal residues: Kinetics of asphaltene decomposition. Fuel 1997, 76, 871-877. [CrossRef]

(C) 2019 by the authors. Licensee MDPI, Basel, Switzerland. This article is an open access article distributed under the terms and conditions of the Creative Commons Attribution (CC BY) license (http://creativecommons.org/licenses/by/4.0/). 